\title{
Decadal changes in the wind forcing over the North Sea
}

\author{
Frank Siegismund ${ }^{*}$, Corinna Schrum
}

Zentrum für Meeres- und Klimaforschung, Universität Hamburg, Troplowitzstr. 7, 22529 Hamburg, Germany

\begin{abstract}
Using data from the NCEP/NCAR reanalysis for the 40 yr period from 1958 to 1997, a wind statistic for the North Sea is derived. This analysis includes consideration of the monthly mean wind speed and decadal variability in angular distribution. The wind density function is introduced, which combines frequency of occurence and mean wind speed for a given direction. The North Sea is subdivided into 3 sectors. Changes in the wind density function for the 3 regions are analysed for 2 seasons, October to January and February to March. The annual mean wind speed for the North Sea shows a rising trend of $\sim 10 \%$ during the last $40 \mathrm{yr}$, mainly restricted to the period from October to March. For October to January, west-southwesterly wind directions are enhanced in the last 3 decades compared to the period from 1958 to 1967 for the whole North Sea area. The last decade from 1988 to 1997 is outstanding: The duration of typical winter wind conditions, with high wind speeds and the prevalence of west-southwesterly winds, is extended from October to January in the first 3 decades towards February and March in the last one. The wind density functions for both seasons investigated and all of the 3 sectors resemble each other in the last decade. In the first 3 decades an enhancement of southerly wind directions is found in the northern part of the North Sea, northward of $59^{\circ} \mathrm{N}$. This trend is broken in the last decade when west-southwesterly directions for the whole North Sea area predominate.
\end{abstract}

KEY WORDS: Wind climate $\cdot$ North Sea $\cdot$ Long-term variability $\cdot$ NCEP reanalysis

\section{INTRODUCTION}

Recently a number of attempts have been made to understand the climate-induced variability of hydrographic and ecological processes in the North Sea. From observations it is known that, for example, temperature and salinity show high inter-annual variability and pronounced periodicity in the frequency band corresponding to periods between 8 and $20 \mathrm{yr}$ (e.g. Sündermann et al. 1994).

Shallow waters like the North Sea are strongly influenced by wind forcing. Recent sensitivity studies employing a shelf ocean model emphasize the strong dependence of transport patterns, and also salt and heat content, on wind forcing (Schrum \& Backhaus

*E-mail: siegis@ifm.uni-hamburg.de
1999, Schrum 1999). It is therefore appropriate to start with investigating the evolution of local wind climate before considering its effect on climate variability on the shelf.

Meteorological evidence suggests that the northeastern Atlantic area is subject to high long-term variability in the synoptic weather system. Rogers (1997) investigated the primary mode of North Atlantic storm track variability using rotated principal component analysis on monthly fields of root-mean-squares of daily high-pass filtered sea level pressures (SLP) for winters 1900 to 1992. He found high positive scores related to high synoptic variability in the area extending from Iceland northeastward to the Norwegian and Barents Sea. The mode itself is associated with low-frequency SLP anomalies in the extreme northeastern Atlantic. Sickmöller et al. (2000) analysed 1979 to 1997 ECMWF re-analysis data and found an increase in 
cyclone density over Scandinavia for this period. This trend seems to be reversed for the southern and eastern part of the North Sea, as can be seen from Fig. 4 of their publication. Long-term changes in wind climate on the regional scale of the North Sea area cannot be deduced from these investigations, because they were performed on a global scale or were restricted to special modes of the atmospheric circulation.

Earlier wind analyses (e.g. those carried out within the WASA project; Langenberg et al. 1997, WASA Group 1997, 1998) were mainly restricted to an explaination of roughening wave climate or growing storm surges; the available data was limited to observations at a few locations and the variables mainly considered were absolute wind speed and the temporal variability of storm occurence and duration.

A more detailed view of observed trends and variability in the wind climate of the North Sea, including wind direction and seasonality during the last decades, is still lacking. The intention of this paper is to fill this gap. Emphasis is put on changes on a decadal time scale in order to obtain useful information about related changes in water mass transport. However, it is not intended to investigate anthropogenic influences on wind climate, as was done within the WASA project.

\section{METHODS}

To provide an overview of decadal changes in the seasonal cycle the monthly wind speed is calculated as an area mean for the North Sea. The most distinct changes and the highest decadal variability are found in the winter period, from October to March, thus this season is investigated in more detail. Since transport processes are not only dependent on the forcing wind speed but also on the wind direction, the following investigation is focussed on the 'wind density function', an angular distribution of the wind speed introduced in section 2.3.

For the sake of clarity, angular distributions are not considered for each respective month. The climatology of the wind density functions (not shown here) reveals that 2 seasons that show similar wind characteristics within themselves can be separated: the period from October to January and the subsequent 2 months, February and March. The first is referred to as the 'winter season', the second as the 'transition period'.

Investigation of cyclone activity (Sickmöller et al. 2000) shows trends in the storm track and cyclone density over northern Europe for the last 2 decades (1979 to 1997), with high gradients over the North Sea suggesting a positive trend for the northern part but a negative trend for the southern part. In the same paper, an increase of stationary cyclones, mainly cen- tered southeast of Greenland, is reported, which may mostly again affect the northern North Sea. In order to investigate regional variability, the North Sea is subdivided into 3 sectors, shown in Fig. 1, named N, W and $\mathrm{E}$, and variability in the wind density function is regarded separately in these regions for both seasons mentioned.

\subsection{Data base}

The calculations carried out in this paper are based on wind speed from the $40 \mathrm{yr}$ NCEP/NCAR re-analysis project (Kalnay et al. 1996). This meteorological data set is available on a T62 Gaussian grid (hence with a resolution of $209 \mathrm{~km}$ ) for the period from 1958 to 1997 with a timestep of $6 \mathrm{~h}$. The North Sea is covered by 28 wet grid points and these are chosen for the present wind statistic. Out of the extensive set of variables the meridional and longitudinal components of the wind speed, calculated for $10 \mathrm{~m}$ height, are chosen as the basis for the following investigations.

\subsection{Mean wind speed}

Firstly, area mean annual and monthly wind speeds were calculated. In the following, $U_{j}^{i}$ and $V_{j}^{i}$ indicate

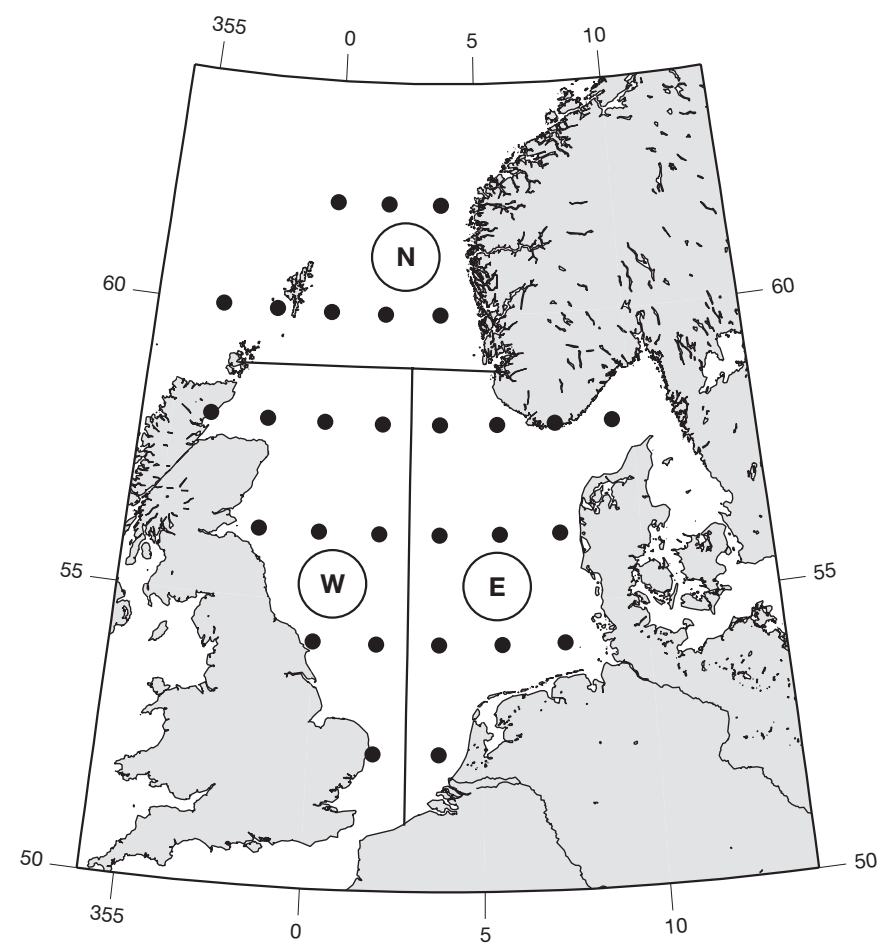

Fig. 1. Grid points of the NCEP reanalysis data used in this paper and sub-division of the North Sea into northern $(\mathrm{N})$, western (W) and eastern (E) sectors for analysing wind density 
the meridional and longitudinal components of the wind speed, respectively, where $i$ stands for the timestep and $j=1, \ldots, N$ is the atmospheric grid point (with $N=28$ as the total number of wet grid points for the North Sea, see Fig. 1). The number of timesteps within the period considered (e.g. a particular month or year) is given by $M_{\text {; }}$ thus, the boundaries of the regarded period are determined by $i_{1}$ and $i_{1}+M$. The mean wind speed is then calculated by:

$$
\bar{v}=\frac{\sum_{j=1}^{N} \sum_{i=i_{1}}^{i_{1}+M} \sqrt{\left(U_{j}^{i}\right)^{2}+\left(V_{j}^{i}\right)^{2}}}{N M}
$$

and is thus defined as an area and time average.

\subsection{Angular distribution; introduction of the wind density function}

To distinguish wind directions with a resolution of $5^{\circ}$, the wind rose is divided into 360/5 = 72 classes. Each event $\left(U_{j}^{i}, V_{j}^{i}\right)$ belongs, depending on its wind direction, to a Class $C(i, j)$. But instead of just counting the events for each class, as it is usually done for a histogram, the wind speeds $V_{j}^{i}=\sqrt{\left(U_{j}^{i}\right)^{2}} \overline{+\left(V_{j}^{i}\right)^{2}}$ of the events are summed up separately for each class. The wind density function $\tilde{a}_{k}$ for the Class $k$ is thus calculated by:

$$
\tilde{a}_{k}=\sum_{c(i, j)=k} v_{j}^{i}
$$

Since the distributions are calculated for different periods with a different number of events, normalization is necessary in order to get comparable results. The normalized wind density function $a_{k}$ is defined as:

$$
a_{k}=\tilde{a}_{k} \frac{\text { number of classes }}{\text { total number of events }}=\tilde{a}_{k} \frac{72}{N M}
$$

so that the mean $a_{k}$ (averaged over the 72 classes), is the mean wind speed for the period under consideration:

$$
\bar{a}_{k}=\frac{\sum_{k=1}^{72} a_{k}}{72}=\bar{v}
$$

According to the definition of $\tilde{a}_{k}$ as a sum of velocities, high values of $a_{k}$ may either result from high wind speeds or they may indicate a high frequency of winds blowing from that direction; low values of $a_{k}$ may either indicate that the wind speed is low or that the wind is rarely blowing from that direction.

Indeed $a_{k}$ can be written as a product of the mean wind speed for Class $k$ and the relative frequency of wind events for this direction. If $F_{k}$ is the number of events in Class $k$, the relative frequency $f_{k}$ derives from normalization:

$$
f_{k}=F_{k} \frac{\text { number of classes }}{\text { total number of events }}=F_{k} \frac{72}{N M}
$$

The mean wind speed $v_{k}$ for Class $k$ is defined by:

$$
V_{k}=\frac{\sum_{c(i, j)=k} V_{j}^{i}}{F_{k}}=\frac{\tilde{a}_{k}}{F_{k}}
$$

Using Eqs. (5) \& (6), $a_{k}$ can be written as:

$$
a_{k}=\tilde{a}_{k} \frac{72}{N M}=\frac{\tilde{a}_{k}}{F_{k}} F_{k} \frac{72}{N M}=v_{k} f_{k}
$$

\section{RESULTS}

The annual mean wind speed for the North Sea for the last 4 decades (1958 to 1997) is shown in Fig. 2. A clear increase of $\sim 10 \%$ is indicated by the regression line, starting from $7.4 \mathrm{~m} \mathrm{~s}^{-1}$ for the late $1950 \mathrm{~s}$ and ending at $\sim 8.1 \mathrm{~m} \mathrm{~s}^{-1}$ in 1997 . The highest year-to-year variability is found in the 1960s and 1980s, with low variability for the $1970 \mathrm{~s}$. The following investigations focus on 3 aspects: seasonality of trend and variability: angular characteristics of the trend; regional characteristics of the trend.

\subsection{Monthly mean wind speed}

The wind climate over the North Sea is characterised by pronounced seasonality: From October to January the mean wind speed is $\sim 9 \mathrm{~m} \mathrm{~s}^{-1}$ (calculated from the 40 yr means not shown here) and $\sim 50 \%$ larger than the velocities in the summer (April to August). On top of this seasonal variability, inter-annual and decadal variability occurs as well. Strongest variability is found in winter, even in relation to the higher mean wind speed compared to the summer season. This may be seen

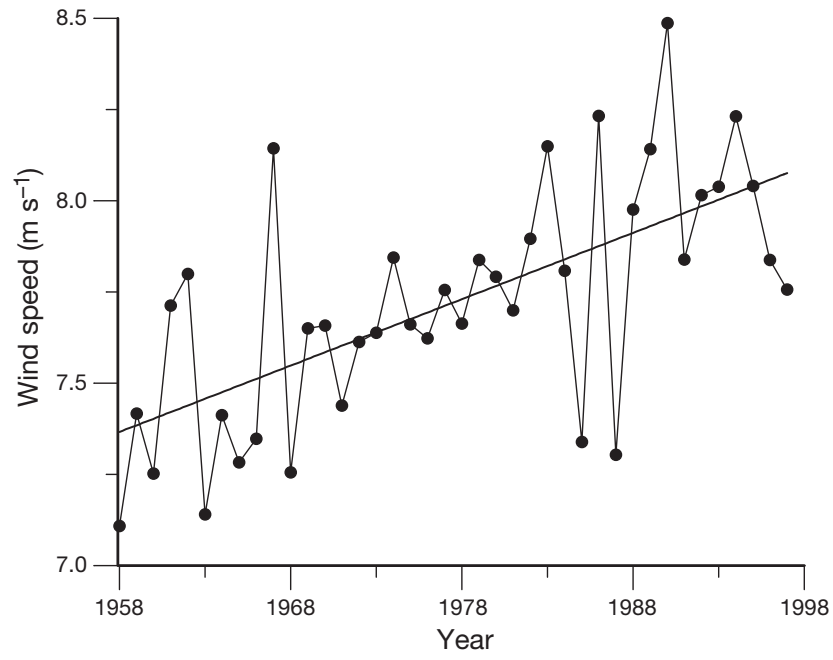

Fig. 2. Time series of the annual mean wind speed over the North Sea, 1958 to 1997 


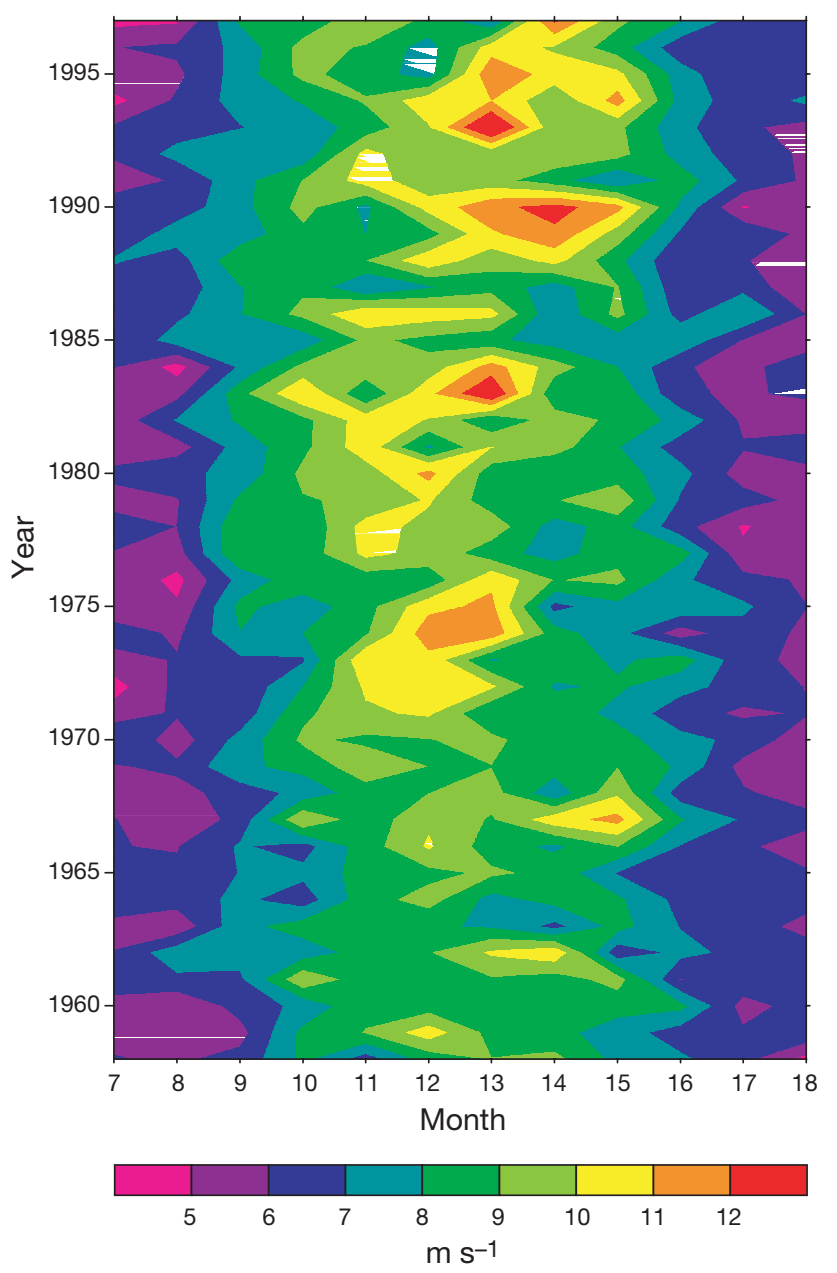

Fig. 3. Monthly mean wind speed for the North Sea, derived from NCEP reanalysis data, 1958 to 1997. Horizontal axis, respective month; winter months centered, 13 to 18 are January to June

from the monthly mean wind speed shown in Fig. 3. To focus on the interesting winter months they are plotted in the center of the figure (the numbers $13,14 \ldots$ are chosen for the months January, February...).

Besides the generally high year-to-year variability, 2 conspicuous features are remarkable: Firstly, since the early 1970s 'strong wind' events (i.e. monthly means $>10 \mathrm{~m} \mathrm{~s}^{-1}$ ) are more frequent than in the 1960s. Secondly, since the mid-1980s, the strong wind events are increasingly found in February and March. The generally increasing wind speed found in the annual means is thus mainly an effect of increasing wind speed in winter. The summer wind speed shows some variability as well, but no pronounced trend to higher values. The following discussions are therefore focussed on the season from October to March, investigating angular characteristics and regional aspects of the trend.

\subsection{Wind density}

In subsection 2.3 the wind density function $a_{k}$ was introduced, an angular distribution for the wind speed that is the product of the mean wind speed $v_{k}$ for a chosen direction $k$ and the relative frequency $f_{k}$ of wind blowing from this direction (see Eq. 7). In this subsection, only the wind density is discussed, for the sake of clarity and because $a_{k}$ is the most useful distribution of the 3 for estimating impacts on exchange processes between atmosphere and ocean, especially the impact on the circulation due to changes in momentum flux. In addition this distribution was good for showing the most distinct variability, because trends in $v_{k}$ and $f_{k}$ are often positive correlated and thus jointly contribute to driving the variability of $a_{k}$.

As already mentioned (cf. Section 2) the season from October to March was subdivided. The motivation for the distinction is that the 'winter season' (October to January) and 'transition period' (February and March) show dissimilar climatologies in wind density for the first 3 decades, and also different trends during this period, but resemble each other in the last decade. This is discussed below in more detail.

\subsubsection{Winter season October to January}

Fig. 4 shows the wind density for the winter season as a mean over $10 \mathrm{yr}$ for each of the 4 successive decades (1958 to 1997) in the 3 sectors of the North Sea (Fig. 1). In the northern sector $\mathrm{N}$ (Fig. 4a) high values are generally found for southerly and southwesterly directions and lower values for wind from the north-northwest. In the segment between north and east-southeast, wind density is near zero. In the 2 sectors for the central and southern North Sea (Sectors W and E, Fig. 4b,c) westsouthwesterly winds predominate while wind from the opposite direction is negligible. The 2 distributions resemble each other, but in Sector E (Fig. 4c) east-northeasterly winds show some significance.

The trend found in the 3 regions is similar. Each of the 3 regions shows a tendency for increasing values for west-southwesterly directions when comparing the first 10 yr (1958 to 1967) with the last 3 decades. In the Regions $\mathrm{E}$ and $\mathrm{W}$ this trend applies through the third decade but is partly diminished in the last.

\subsubsection{Transition period February to March}

The angular distribution for the transition period is given in Fig. 5. For sector $N$, the wind density during the first 3 decades is similar to the winter season, but for the second and especially the third decade it is 

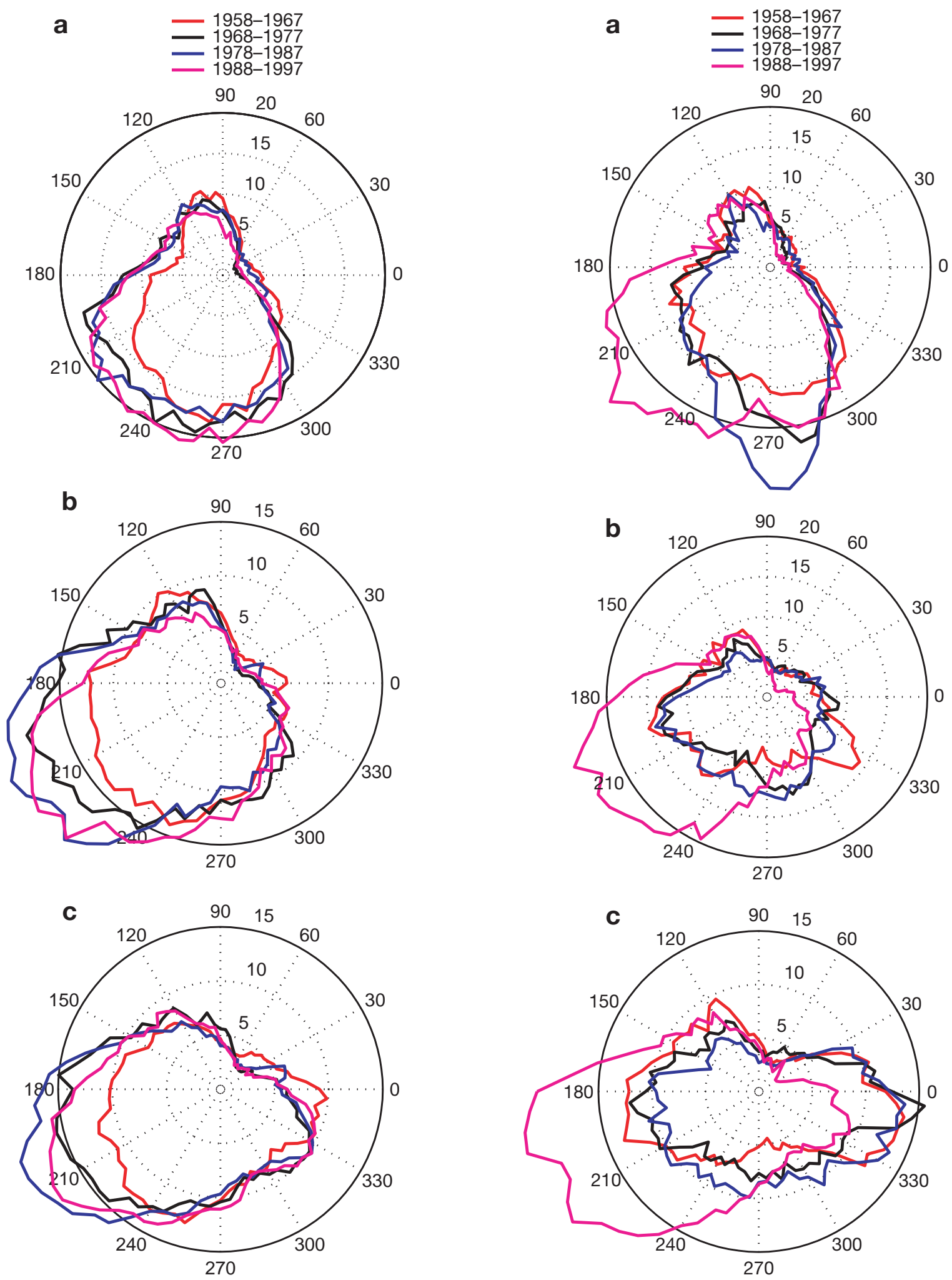

Fig. 4. Normalized wind density functions for the winter season (ONDJ) for each of the 4 decades from 1958 to 1997 , derived from NCEP reanalysis: (a) northern North Sea, Sector N, (b) western North Sea, Sector W, (c) eastern North Sea, Sector E. For sectors see Fig. 1

Fig. 5. Normalized wind density functions during the transition period (February and March) for each of the 4 decades from 1958 to 1997, derived from NCEP reanalysis: (a) northern North Sea, Sector N, (b) western North Sea, Sector W, (c) eastern North Sea, Sector E. For sectors see Fig. 1 
even more concentrated around southerly directions. In Sectors $\mathrm{W}$ and $\mathrm{E}$, wind distribution is quite different from that in the winter season. For the first 3 decades Sector E shows a pattern with zonal orientation, highest values for easterly directions and some lower values from the west, while Region W shows, for the same period, highest values for the segments from the west and south but there is no pronounced preference for a certain direction.

Regarding the trends, 2 features can be separated, one that is a common feature for the whole North Sea and one that is peculiar to the northern North Sea: (1) In all of the 3 regions the wind density for the last decade is quite different from that of the 3 decades preceding. A jump to high values for west-southwesterly directions appears; the resulting distribution is similar in each of the 3 sectors. (2) In region $\mathrm{N}$ a successive increase in the wind density is found for southerly directions in the first 3 decades. This trend is partly diminished in the last decade, when the wind density jumps up to a preference of west-southwestern directions.

\section{SUMMARY AND DISCUSSION}

The wind climate over the North Sea has changed substantially during the past 4 decades. Three features can be separated: (1) An intensification of west-southwesterly wind directions in the winter season (October to January), comparing the decade from 1958 to 1967 with the subsequent 30 yr (1968 to 1997), for the whole North Sea. (2) An extension of the winterly wind climate towards February and March during the last decade (1988 to 1997), with pronounced preference for west-southwesterly wind directions, also for the whole North Sea. (3) A successive positive trend for southerly winds during the first 3 decades (1958 to 1987) in the northern North Sea.

To find the teleconnections between changing wind climate over the North Sea and the North Atlantic large scale circulation is beyond the scope of this paper. Potential explanations derive from the winter index of the North Atlantic Oscillation (NAO). This index is based on the difference in normalized sea level pressure between Lisbon, Portugal and Stykkisholmur, Iceland (see Hurrell 1995). In Fig. 6 the index for the last $40 \mathrm{yr}$ is plotted together with the mean wind speed for the North Sea area. Both NAO index and wind speed are averaged over the period from December to March for each respective year. The correlation between the 2 time series is 0.69 , indicating a possible link: Since NAO is a large scale dipolar pattern with a high pressure pole in the south (Portugal) and low pressure in the north (Iceland), an increasing

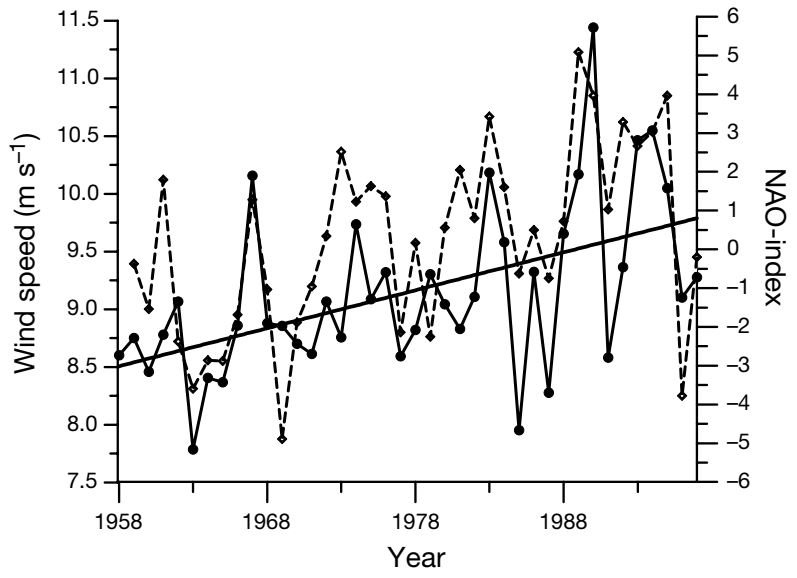

Fig. 6. Time series of winter mean wind speed (December to March) over the North Sea for 1958 to 1997, derived from NCEP reanalysis (solid line), and the winter NAO index (dashed line). The solid straight line indicates the trends for both time series during that period calculated by linear regression

index leads to strengthening westerly winds. Moreover, the NAO index is positively correlated to the number of nearly stationary cyclones centred southeast of Greenland (Sickmöller et al. 2000). This may be related to the increase in southerly wind directions for the northern North Sea.

The continuously increasing mean wind speed during the past 40 yr may suggest an anthropogenic origin, but this hypothesis can neither be supported nor disproved by analysing such short time series. For the NAO index, inter-annual cycles with periods of 2,8 , 24 and also 70 yr have been found (Hurrell \& van Loon 1997, Cook et al. 1998). Distinguishing natural variability from long term trends needs long time series comparable to the half period of the slowest cycle, which is presently not known for the NAO, but is at least $35 \mathrm{yr}$. Another problem occurs since increasing predominance of westerly winds may be a part of climate change that is not indicated by the NAO index: Simulations of climate change due to increasing greenhouse gases suggest a northeastward shift of the northern variability centre, leading to more storm activity over northwestern Europe, this cannot be seen in the index because it is based on measurements fixed in space (see Ulbrich \& Christoph 1999).

Whether anthropogenically induced or not, an increasing NAO, such as that observed for the last 4 decades, is an expected result from the greenhouse scenario when assuming increasing atmospheric $\mathrm{CO}_{2}$ concentration. Thus, by looking at the changing climate for the last $40 \mathrm{yr}$ on the regional scale of the North Sea, we not only get a link to the large scale North Atlantic climate but also may get hints to possible consequences of climate change on the regional scale. 
The influence of increasing westerly winds found in our studies was investigated within a numerical sensitivity experiment for the North Sea and the Baltic Sea (Schrum 2001, this issue), where an intensification of the cyclonic circulation was found to be linked to increasing exchange with the northern Atlantic and therefore increasing salt content of the North Sea. Earlier studies have tried to link ecosystem processes to climate variables, e.g. the catches of horse mackerel Trachurus trachurus in the northern North Sea are found to be correlated to the inflow conditions into the North Sea (Iversen et al. 1998), or the abundance of Calanus finmarchicus, which was found to be related to the NAO (Reid et al. 1998). In combination, these studies could give indications about the possible impact of anthropogenic changes on the North Sea and its ecosystem. However, further investigations of changing atmospheric condition on the regional scale related to the large scale climate and their impact on hydrographic and ecological parameters are desirable.

Acknowledgements. We are grateful to Bob Dickson for valuable dicussions, and to Thomas Pohlmann and Ute Luksch for critical revision of the draft. The NCEP reanalysis data is provided by the NOAA-CIRES Climate Diagnostics Center, Boulder, Colorado, freely available from their web site at http://www.cdc.noaa.gov/. The work was financed partly by the German Science Foundation in the framework of the Collaborative Research Centre (SFB) 512 and by the Universität Hamburg.

\section{LITERATURE CITED}

Cook ER, D'Arrigo RD, Briffa KR (1998) A reconstruction of the North Atlantic Oscillation using tree-ring chronologies from North America and Europe. The Holocene 8(1):9-17

Hurrell JW (1995) Decadal trends in the North Atlantic Oscillation: regional temperatures and precipitation. Science 269:676-679

Submitted: December 22, 1999; Accepted: March 20, 2001
Hurrell JW, van Loon H (1997) Decadal variations in climate associated with the North Atlantic Oscillation. Clim Change 36:301-326

Iversen AS, Skogen MD, Svendsen E (1998) Influx of Atlantic water and feeding migration of horse mackerel. ICES C.M. 1998/R:18

Kalnay E and 18 others (1996) The NCEP/NCAR 40-year reanalysis project. Bull Amer Met Soc 77(3):437-471

Langenberg H, Pfizenmayer A, von Storch H, Sündermann J (1997) Natural variability and anthropogenic change of storm related sea level variations along the North Sea coast. External report 48/97, GKSS Research Centre, Geesthacht

Reid PC, Planque B, Edwards M (1998) Is observed variability in the long-term results of the continuous plankton recorder survey a response to climate change? Fish Oceanogr 7:282-288

Rogers JC (1997) North Atlantic storm track variability and its association to the North Atlantic Oscillation and climate variability of northern Europe. J Clim 10:1635-1647

Schrum C (2001) Regionalization of climate change for the North Sea and the Baltic Sea. In: Sündermann J, Lenz W (eds) Impact of climate change on the coastal zone. CR SPECIAL 10. Clim Res 18:31-37

Schrum C, Backhaus JO (1999) Sensitivity of atmosphereocean heat exchange and heat content in the North Sea and the Baltic Sea. Tellus 51A:526-549

Sickmöller M, Blender R, Fraedrich K (2000) Observed winter cyclone tracks in the northern hemisphere in re-analysed ECMWF data. Q J R Meteorol Soc 126:591-620

Sündermann J, Becker G, Damm P, van den Eynde D, Frohse A, Laane $R$, v. Leussen W, Pohlmann T, van Raaphorst W, Radach G, Schultz H, Visser M (1994) Decadal variability on the Northwest European Shelf. Dtsch Hydrogr Z 48: $365-400$

Ulbrich U, Christoph M (1999) A shift of the NAO and increasing storm track activity over Europe due to anthropogenic greenhouse gas forcing. Clim Dyn 15:551-559

WASA Group (1997) Changing waves and storms in the Northeast Atlantic? External report 46/97, GKSS Research Centre, Geesthacht

WASA Group (1998) Changing waves and storms in the Northeast Atlantic? Bull Am Met Soc 79:741-760

Proofs received from author(s): July 10, 2001 